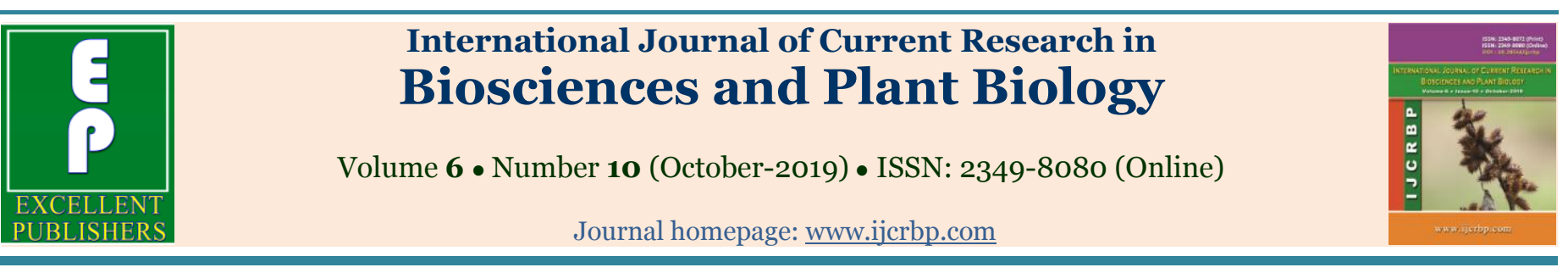

Review Article

doi: $\underline{\text { https://doi.org/10.20546/ijcrbp.2019.610.002 }}$

\title{
Human anthropometric values and societal factors - A review
}

\author{
Adamu Jibril Bamaiyi* and Kabiru Abdullahi Ladan
}

\author{
Department of Physiology, Faculty of Basic Medical Sciences, College of Health Sciences, \\ Usmanu Danfodiyo University, Sokoto, Nigeria \\ *Corresponding author; e-mail: adamu.jibril@udusok.edu.ng
}

\begin{tabular}{|c|c|}
\hline Article Info & ABSTRACT \\
\hline $\begin{array}{l}\text { Date of Acce } \\
15 \text { September }\end{array}$ & \multirow{7}{*}{$\begin{array}{l}\text { Anthropometric measurements have important applications in every aspect and stage of } \\
\text { the human life. It may be used to tell-tale the health or otherwise during pregnancy of the } \\
\text { mother and the unborn baby. During childhood, it can be used to measure growth, health } \\
\text { and nutritional status. In adult life, they may depict level of nourishment and may } \\
\text { connote some disease states. The records are required in drugs prescription and in } \\
\text { designing and choosing the right hospital equipment to use for a patient. Anthropometric } \\
\text { measurements are also required in the design of houses, human wears and most } \\
\text { industrial designs of products for human uses are based on average anthropometric } \\
\text { records of the particular society for which they are meant. A particular anthropometric } \\
\text { index however, may vary widely between apparently normal individuals of the same sex, } \\
\text { age and race when varying from one societal setting to the other and sometimes within } \\
\text { same society based on some factors. These differences often make it difficult to interpret } \\
\text { anthropometric measurements as normal or abnormal. What are the determinants of } \\
\text { these differences? How should these variations be managed by health workers and other } \\
\text { users? The present review intends to present some of these differences in various human } \\
\text { categories and suggest in a compact, yet comprehensive form, how to deal with these } \\
\text { differences in order to optimize the use of the records. }\end{array}$} \\
\hline & \\
\hline Keywords & \\
\hline & \\
\hline & \\
\hline & \\
\hline & \\
\hline
\end{tabular}

\section{Introduction}

To date, anthropometric measurement is the longest standing measurement of human variations (Ulijaszek and Komlos, 2009). Although, only in the nineteen century was anthropometric measurements quantitatively documented, the justification to recognize variations in humans has existed and has being in use since the existence of mankind (Ulijaszek and Komlos, 2009). Anthropometric measurements are easy, cheap, non-invasive, standard and acceptable procedures for assessing the composition of the human body (WHO, 1995). Its measurements comprise among others, height, weight, mid-upper arm circumference (MUAC), occipito-frontal circumference (OFC), body mass index (BMI) and body fat mass. Anthropometric records can be used to predict nutritional status, health and survival in all human categories (WHO, 1995; Albulescu et al. 2012). Some anthropometric variables show association between stability of physical traits and personality of the individual (Carmen, 2012). Moreover, designers and ergonomists also depend on anthropometric values to design facilities for the end users (Albin, 2013; Ismaila, 2009). 
The records can be used to evaluate nutritional status and growth in children (Laghari and Nizamani, 2009; WHO, 1995; Vickers and Stuart, 1943; Janssen et al. 2004). Maternal anthropometry may predict her haemoglobin/ haematocrit levels in the third trimester of pregnancy and it correlates with feto-maternal outcome and infant morbidity and mortality (Bamaiyi et al., 2013; Lawoyin, 1997). MUAC has been reported to be strongly correlated with weight among healthy non-pregnant women (Bamaiyi et al., 2015). And when adjusted for age and sex, OFC showed a positive correlation with brain volume and cognitive functions (Rollins et al., 2010; Cooke et al., 1977). However, this relationship rapidly loses value with decrease in OFC during early childhood (Vickers and Stuart, 1943).

While there are evidences that Body Mass Index (BMI), an anthropometric index that is popular in assessing weight for height, may be affected by age and gender on one hand, ethnicity or race on the other hand does not (Gallagher et al., 1996), it has been shown in another study that race, economic and dietary factors may interact to influence the size of children (Vickers and Stuart, 1943). Similarly, Lagiou and colleagues (2003) reported that Chinese who migrated to USA are bigger and their babies tend to have higher birth weight. To this extent therefore, anthropometric results requires careful interpretation from one society to another or one economic class to another, as well as in the same society, even though the outcomes of subnormal anthropometries on morbidity and mortality is well established (Grellety and Golden, 2016). It is therefore necessary that we ask the question, what will be the criteria for deciding a reference range for the normalcy of anthropometric results for a specific group of apparently healthy individuals?

The present review highlights some of the variations that are obtained in otherwise normal groups from some selected societal settings. In this regard, some anthropometric variables in Nigeria have been compared with some other countries outside Africa to explore possibility of race and environmental influences on the records (Vickers and Stuart, 1943; Sengupta and Karmakar, 2007). Similarly, variables from the northern and southern Nigeria have been examined, because these regions are distinct in many environmental variables including, weather, level of education and socio-economic status and may present with differences in anthropometric characters (Bamaiyi et al., 2016; Bharati et al., 2005; Pingle, 1984). This review also discussed criteria that may be used for this purpose, highlighting the pros and cons.

\section{Variations in anthropometric variables}

A range of factors interact at various levels that result in variation in anthropometric records between societies even if they are of same race, sex and age (Luke et al. 1997). To this extent, some anthropometric variations have emerged following the interactions of these factors giving a peculiar phenotype and personality to some groups based on some defined criteria (Carmen, 2012). It is therefore necessary to recognize these differences and when reference ranges for anthropometric variables are made for a particular society or group, it should be done to accommodate their peculiarities. Besides, global westernization with its associated awareness and improved health education might have aided consciousness in the body look, necessitating reconsideration of anthropometric reference ranges. In the present review, some anthropometric variables were compared between three different populations; a developed country and two different geo-political regions within Nigeria (a developing country). These are as shown in Figs. 1-3.

\section{Anthropometric Variables as Indices of Well-Being/Diseases at Various Stages of Development}

\section{During pregnancy}

Weight gain: A progressive and optimum weight gain in pregnancy is not only an indication of the normalcy of a pregnancy but it may be a fortune teller on other parameters in pregnancy (Godhia et al., 2012; Deval et al., 2011; WHO, 2001; Lawoyin, 1997). Whether the weight gain is appropriate or not may also predict pregnancy outcomes, such as birth weight, risk of pre-term birth and some disease condition later during adult life of the foetus (McDonald et al., 2010; Lawoyin, 1997; Calkins and Devaskar, 2011). Nevertheless, the values of weekly weight gains considered as normal may vary when varying from one population of 
pregnant women to another and even among pregnant women considered as similar (Galjaard et al. 2013). Some examples are shown in Fig. 1a below.

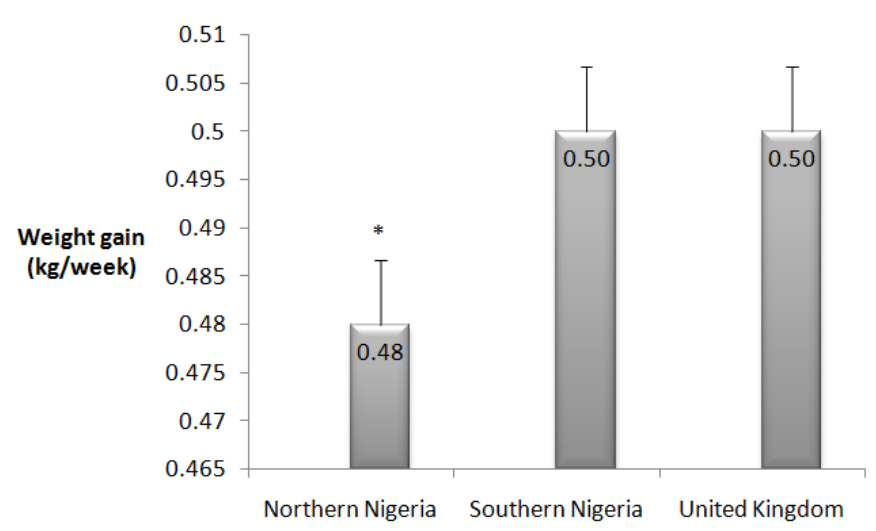

Fig. 1a: Average weight gains in pregnancy (Bamaiyi et al. 2013; Lawoyin, 1991, Borton, 2009)

$\boldsymbol{B M I}$ : This is a more acceptable measure of obesity by the World Health Organization (WHO) and the Institute of Medicine (IOM) (Monte et al. 2011). BMI values in pregnancy are not only associated with feto-maternal outcomes but may account for metabolic diseases in the child in future or what is regarded as fetal origin of adult diseases hypothesis of Barker (Calkins and Devaskar, 2011).

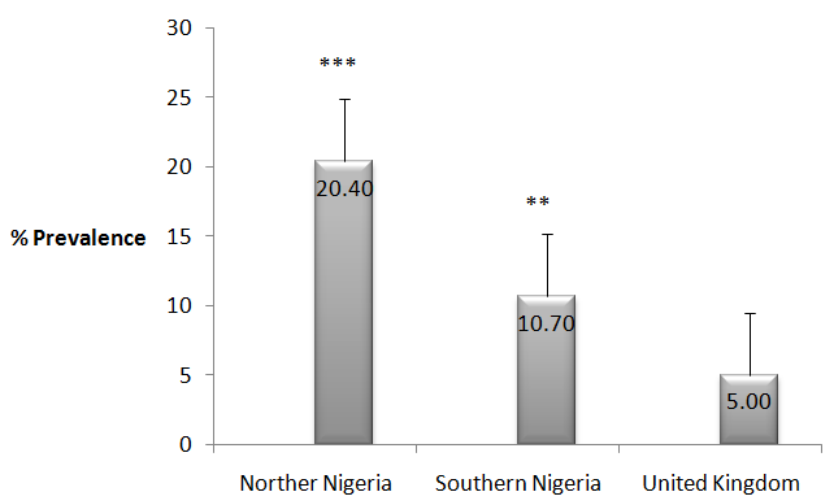

Fig. 1b: Prevalence of obesity in pregnancy (Bamaiyi et al., 2015; Chigbu and Aja, 2011; Morgan et al., 2014).

Moreover, a systematic review and meta-analyses have shown that the effects of BMI on pregnancy outcomes showed variations between developed and developing countries (McDonald et al. 2010). As important as this anthropometric variable is in pregnancy, it is obvious that what is a normal record in one setting may not be absolutely so in another category of pregnant women (Monte et al.,
2011; Rasmussen and Yaktine, 2009; Leddy et al., 2008; Ricalde et al., 1998). See some variations studied in apparently normal pregnant women in Fig. 1b.

MUAC: This is the anthropometric variable of choice for determining womenat risk during pregnancy (Ververs et al., 2013; Ricalde et al., 1998). Because it is relatively stable during pregnancy and it represents the woman's fat and lean body mass (WHO, 1991; Bamaiyi et al., 2013). However, Ververs and colleagues (2013) observed that pregnant adolescents because of difference in physiology compared to older women, may have different MUAC and they also observed that variations may be observed when varying from one country to another. Some of these variations examined are shown in Fig. 1c below.

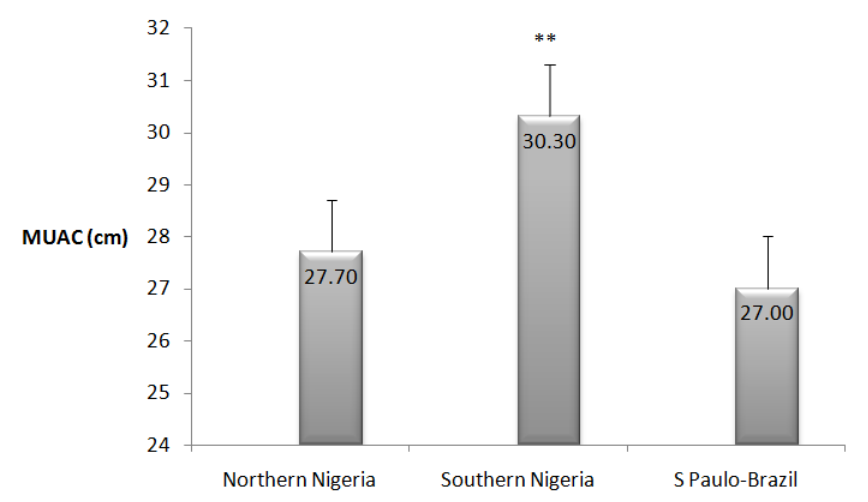

Fig. 1c: Average MUAC in pregnancy (Okereke et al. 2013; Bamaiyi et al. 2013; Recalde et al. 1998)

\section{During childhood}

Weight: This is a good parameter of evaluating growth and nutritional status during childhood (Ulijaszek and Komlos, 2009). Similarly, birth weight is an important factor associated with child morbidity and mortality as well as organic diseases during the child's adult life (Calkins and Devaskar, 2011). It is also a vital instrument for assessing the health care delivery system of a nation (Onankpa et al., 2006). Meanwhile, significant differences in normal weights at birth and weights during childhood were observed across races in a study carried out by Wilcox and colleagues (1993). Moreover, within Nigeria it was for instance reported that normal child birth weights also vary from one geo-political region or ethnicity to another (Patwari et al., 1988; Onankpa et al., 
2006). These disparities may not be unconnected with differences in sex of the babies, maternal race and age, smoking habits, alcohol consumption, presence of gestational diabetes and socioeconomic status (Amini et al., 1994; Onankpa et al., 2006; Ndu et al., 2014; Wilcox et al., 1993). Some birth weights variations studied are as shown in Fig. 2a below.

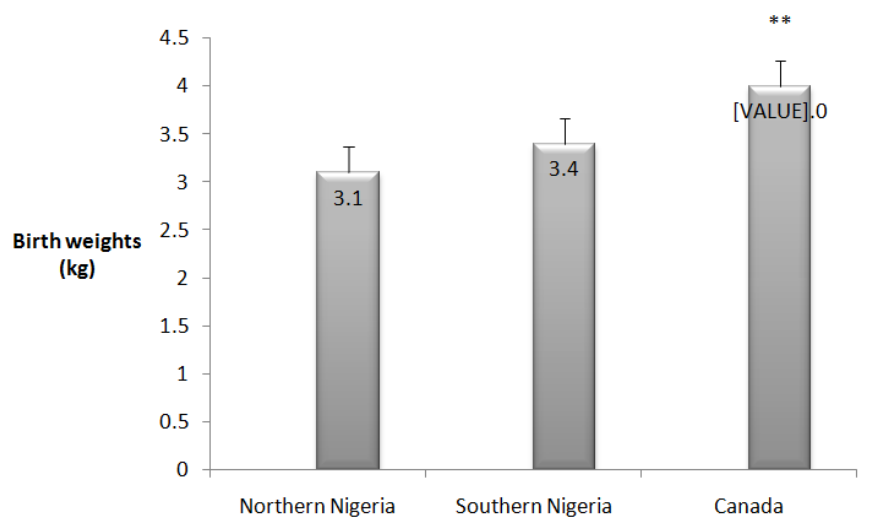

Fig. 2a: Average birth weights (Onankpa et al., 2006; Olusanya, 2013; Kramer et al., 2001).

Birth length and child height: The neonate's birth length like some other anthropometric measurements correlates with birth weights. Suboptimum values therefore may account for prevalence of childhood morbidity and mortality (Mutihir and Pam, 2006; Onankpa et al., 2006). Similarly, the child's height for age pattern is considered as road to health. Nevertheless, the value varies according to the environmental, genetic and epigenetic factors around the any particular child. Therefore, a single harmonized value is difficult to arrive at; necessitating setting normal reference ranges that fit into different groups. A few variations in different settings have been compared here and presented in Fig. 2 b.

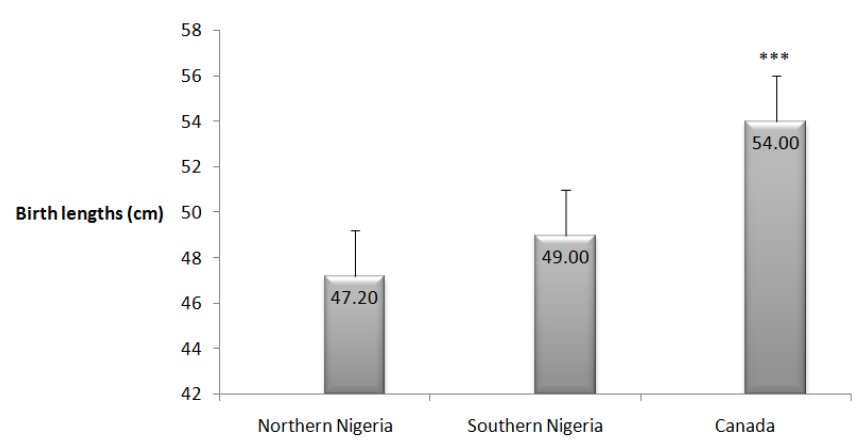

Fig. 2b: Average birth lengths (Mutihir and Pam, 2006; Oluwafemi et al., 2013; WHO, 2014).
OFC: Although its application is limited as a child grows (Vickers and Stuart, 1943), it is a surrogate for birth weight (Jonathan et al., 2010). It also correlates with brain weight and intelligence quotient (IQ) (Silventoinen et al., 2012; Jonathan et al., 2010; Cooke et al., 1977). Nevertheless, what is considered as normal reference range for this important anthropometric measurement has a very wide range, as one moves from one human category to another. Therefore, some models in earlier studies have been compared and shown in Fig. 2c below.

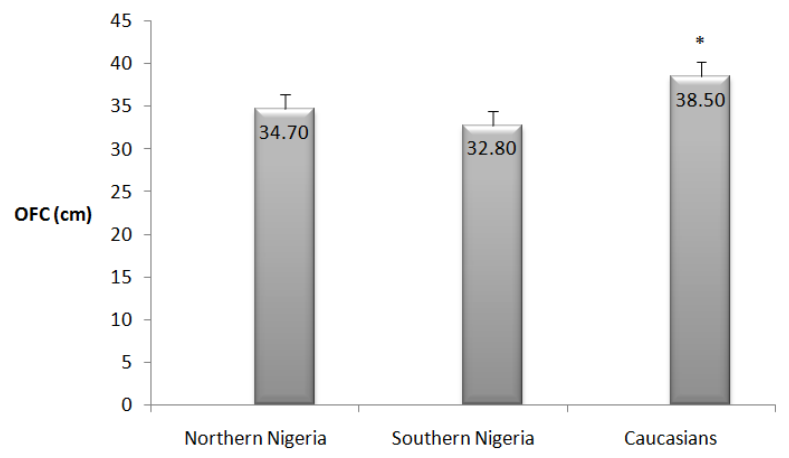

Fig. 2c: Average OFCs at birth (Patwari et al. 1988; Ndu et al., 2014; CDC, 2001).

MUAC at birth: This is a reflection of maternal nutrition and anthropometry during pregnancy (Bob-Manuel and Udoaka, 2008). Although, a study by Dairo and colleagues (2012) reported that this is not completely valid. The latter study also suggested expanding the normal reference range for MUAC of children to improve its validity. During childhood, MUAC connote nutritional status and health status of the child (Bamaiyi et al., 2015). Some variations in the normal values of MUAC of neonates at birth have been reviewed and are presented in Fig. 2d below.

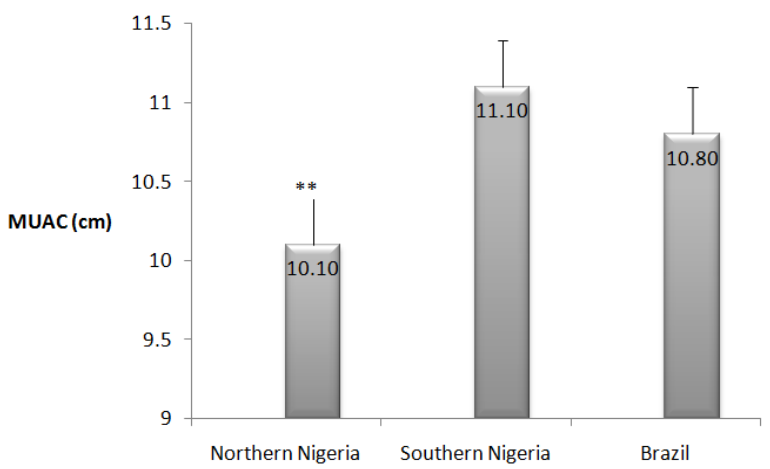

Fig. 2d: Average MUACs at birth (Eregie, 1991; Achebe et al., 2014; Figueira and Segre, 2004). 


\section{During adulthood}

It is important to note that most anthropometric measurements in adults exhibit sexual dimorphism. To this extent, both male and female values are presented here separately.

Weight and height: The weight or height as a measure of anthropometry in the adults is better presented together, in an index known as body mass index $\left(\mathrm{BMI}=\right.$ weight $/$ height $\times$ height, $\left.\mathrm{kg} / \mathrm{m}^{2}\right)$. $\mathrm{BMI}$ is used to determine risks of organic diseases like hypertension, type II diabetes and dyslipidaemia and to project mortality (Chittawatanarat et al., 2011; Calle et al., 1999). The average adult weight or height for a particular setting is determined by a number of prevalent factors in such setting. Therefore, socially and economically stable societies interacting with genetic and epigenetic factors will have individuals well-nourished to attain their full growth potentials, compared to societies that are characterized by poverty and infectious disease conditions which will result in stunted growth.

Often, these modifications in the phenotype stabilize to become a physical trait. In this regard, the mean values of weights and heights in apparently normal adults vary from one setting to another and sometimes within a setting due to variations in some well-defined confounders. The present review has verified some of the variations in the weight and height in apparently normal subjects and compared these among values obtained in different settings and are presented in Figs. $3 \mathrm{a}$ and $3 \mathrm{~b}$ below.

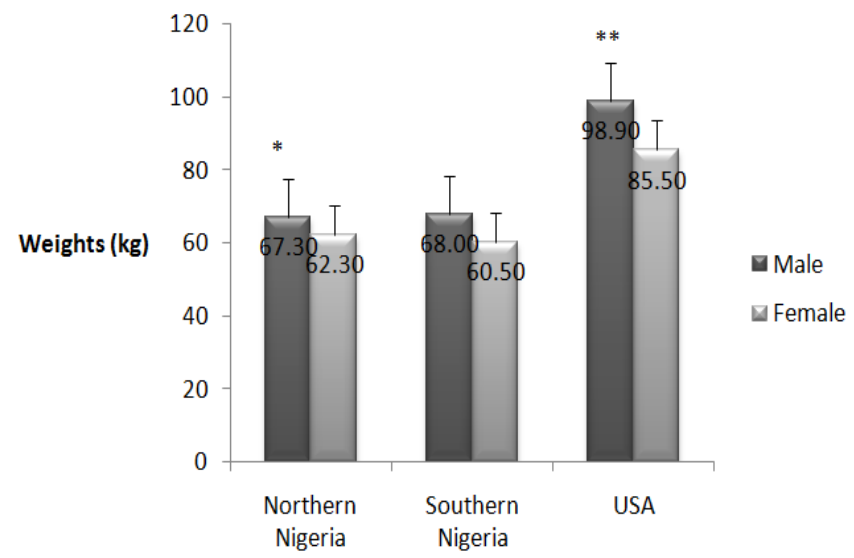

Fig. 3a: Average adult weights (Ekedigwe et al., 2014; Algiri et al., 2008; Fryar et al., 2012).

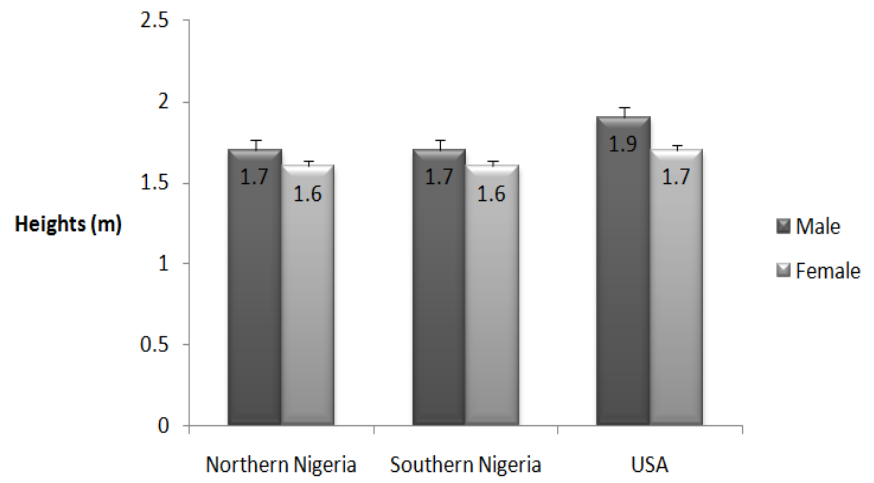

Fig. 3b: Average adult height (Ekedigwe et al., 2014; Algiri et al., 2008; Fryar et al., 2012).

Body fat mass index (BFMI): This anthropometric index may serve as surrogate for BMI in evaluating risks of diseases of metabolic syndrome and the associated mortalities (Calle et al., 1999; Schutz et al., 2002). However, what can be considered as normal will depend on the sex, and age of an individual (Olorunshola et al., 2013; Luke et al., 1997; Schutz et al., 2002). Moreover, people of same sex and age have been found to exhibit wide range of values outside what some reports have set as normal reference ranges, as a result of interactions of some factors. Some of the variations obtained in different settings in previous studies are presented in Fig. 3c below.

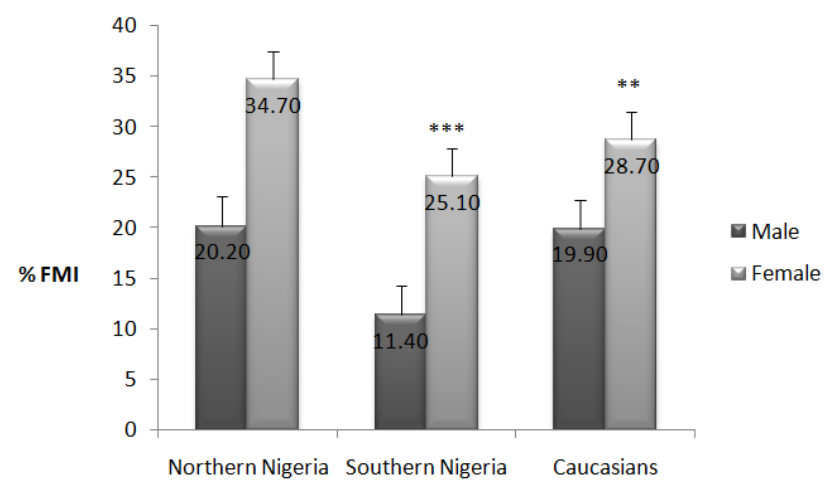

Fig. 3c: Average body fat mass indexes (FMI) (Olorunshola et al., 2013; Luke et al., 1997; Schutz et al., 2002).

Foot length: The foot length can be used to predict the hand length and it correlates well with the stature of an adult individual (Danborno and Elukpo, 2008; Krishan and Kanchan, 2013; Pawar and Pawar, 2012). This measurement is important in reconstructive surgeries, design of footwears and of other appliances where the length of the foot requires to be known (Ismaila, 2009, Pawar 
and Pawar, 2012). The average foot lengths in apparently normal people of different settings show variations and have been documented in some previous studies (Fig. 3d).

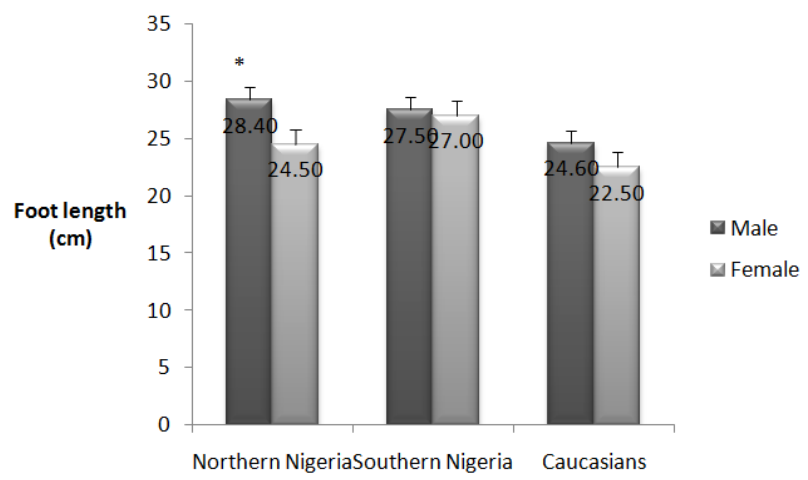

Fig. 3d: Average adult foot lengths (Danborno and Elukpo, 2008; Ismaila, 2009; Pawar and Pawar, 2012).

Waist circumference: It is increased with increase in body adipose tissues and correlates with BMI (Adamu et al., 2013; Chinedu et al., 2013). Waist circumference is considered an obligatory component in defining metabolic syndrome (Ghazali and Sanusi, 2010) and its inclusion in routine general medical examination has been advocated (Ford et al., 2014; Ghazali and Sanusi, 2010). Yet, what is considered normal reference values varies from one setting to the other. Some of the waist circumferences studied is as shown in Fig. 3e.

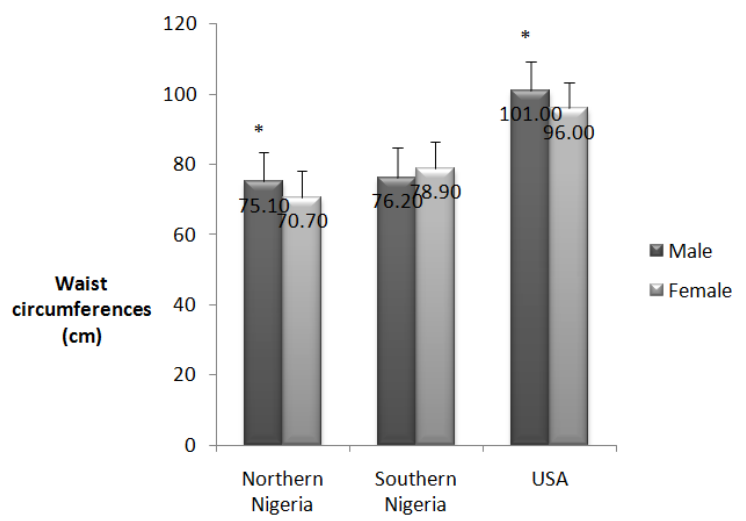

Fig. 3e: Average adult waist circumferences (Adamu et al., 2013; Chinedu et al., 2013; Ford et al., 2014).

\section{Determinants of variations in anthropo- metric values in different societal settings}

While it is clear that anthropometric measurements may tell-tale the health conditions of an individual, sub-optimum values obtained sometimes are not necessarily due to disease or deficiency conditions. But they might have arisen because of the interplay of factors around such person and then stabilized in the phenotype (Wang et al., 2006; Wang and Chen, 2012). The intensities of the factors that could affect anthropometric characters are not uniform across the world nor are they the same in a given society. In this regard, in apparently normal persons the anthropometric records obtained will be a product of the interactions of the determining factors. The following are some of the factors that may determine the differences observed in anthropometric variables:

\section{Gender}

Many anthropometric variables, especially in adults display sexual dimorphism (Olorunshola et al., 2013). Thus, under similar conditions, male features are often found to be longer, heavier and wider than their female counterparts (Ekedigwe et al., 2014; Fryar et al., 2012). Relethford and colleagues (1980), also found in a study conducted in Ireland that environmental variations influence the anthropometric characters of the female participants more than their male counterparts.

\section{Genetic factors}

The phenotype of human body is a product of the interactions between the genetical make-up and environment factors (Silventoinen et al., 2012; Pingle, 1984; Relethford, 1988; Sengupta and Karmakar, 2007; Balgir, 2003). Moreover, a study among twins in Minnesota, showed a consistent correlation between height and OFC and intelligent quotient (IQ) and it was explained to be due to the common genetical factors (Silventoinen et al., 2012).

\section{Geographic location}

A geographic setting describes a collection of a particular population in a location that has some factors influencing them in common. The factors together act to influence their body composition and will confer on them some anthropometric records which will be at variance with those who are not from same geographic location with them (Bharati et al., 2005). 


\section{Environmental factors}

The environment, which include accessibilities to nutrition and modern day technology which determine growth rate and calories use, respectively may account for the variations in the anthropometric characteristics recorded as one moves from one setting to another (Sengupta and Karmakar, 2007). To this extent, it was reported that inter-settlements migrations caused a reduction in variations in anthropometric variables between different environments in a study carried out in Ireland (Relethford et al., 1980; Lagiou et al., 2003).

\section{Climatic factors}

The appearance of the human body is a reflection of the evolutionary adaptations which were inculcated over time in order to adjust to the climatic conditions of where the individual is found (Adak, 2004). Thus, annual rain intensity, degree of humidity, altitude and temperature will all entail human adjustments and will affect the appearance of the individual that may eventually stabilize into his/her anthropometric records (Bharati et al., 2004; Pingle, 1984; Relethford, 1988; Sengupta and Karmakar, 2007; Balgir, 2003; Adak, 2004).

\section{Anthropometric cut-off points in the light of accommodating more normal variants and enhancing user friendliness}

Reports have shown that normal variants in anthropometric records occur on a wide range of values. Although it is a lot easier to choose a global cut-off point for anthropometric variables that may be used to compare records around the world (Wang and Chen, 2012), but it must be considered that this may 'short-change' some normal variants who had arisen from adaptations that have stabilized overtime, due to interactions of some determining factors around them (Carmen, 2012). It is also important to acknowledge that the need to understand the implications of the records should consider other users and not only among the statisticians.

Anthropometric records are meant to show associations not causations to the health or disease status of individuals (Wang and Chen, 2012; Kuhle et al. 2015). Therefore, to accommodate the disparate nature of factors that determine the records between and within societal settings coupled with the current trends of changes in anthropometry in human concomitant with urbanization in the developing countries, adjustment in reference cut-off points for anthropometric variables is due (Dairo et al., 2012; Wang and Chen, 2012).

Percentiles and Z-scores are the most popular statistical tools used in expressing reference cut-off points in anthropometric measurements (Wang and Chen, 2012). While the Z-scores has the merits of being handy in handling different variables among different ages and sex, it may not be understood easily by the wider public and it is not a popular tool among clinical users (Wang and Chen, 2012; Bowman, 2002). The percentile ranks on the other hand, may require drawing different population distribution curves for different variables, ages and sex and therefore lack the brevity of Z-scores, so it is not popular among statisticians. The percentiles ranks however, is easily understood by the public and more acceptable in the clinical setting (Wang and Chen, 2012). Moreover, the percentiles distribution curves are based on normal distributions. The Zscores values estimate the number of standard deviations (SD) and the directions (positive or negative) a particular variable is away from the population's mean value, and may therefore be derived from the percentile distribution curve around the peak/mean/zero point of the curve (Wang and Chen, 2012). The percentile to use however should be guided by the purpose of the study. In this regard, epidemiological reports may consider higher percentiles such as $97.7^{\text {th }}$ to $95^{\text {th }}$ and when disease risk estimation is sought, a more conservative percentile of $<95^{\text {th }}$ may be considered. It is also important to note that for every percentile on a normal population distribution curve (which enhances the understanding), there is a predictable value corresponding to $\mathrm{Z}$-scores value for it(Wang and Chen, 2012; Bowman, 2002).

\section{Conclusion}

The present review compared human anthropometric values between Northern and Southern Nigeria and compared these with those of an advanced country to explain the extent of 
variations. The review also emphasis the need to expand reference ranges for anthropometric variables. And it was further suggested the use of percentile ranks to set cut-off points, because of its user friendliness and wider conversance. Furthermore, it has been explained in the review that the percentile to choose should be dictated by the purpose of the study (epidemiological study or risk stratification) (Kuhle et al., 2015). To this extent, the reference ranges for anthropometric variables need to be expanded to accommodate the many disparate normal variants as we hover between different societal settings. It is also noteworthy to emphasize that the problem with 'abnormal' anthropometric records is not in the phenotype itself, instead it is the consequence. Therefore, the range of values that result in untoward consequences in a scientifically significant portion of the population under consideration may be considered as abnormal for such population.

\section{Conflict of interest statement}

Authors declare that they have no conflict of interest.

\section{References}

Achebe, C., Ugochukwu, E.F., Adogu, P.O.U., Ubajaka, C., 2014. Prediction of low birth weight from other anthropometric parameters in Nnewi, south eastern Nigeria.Niger. J. Paed. 41 (1), 59-63.

Adak, D. K., 2004. Variation in anthropometric characters and their relationship with climatic factors: a study on the peoples of Arunachal Pradesh, India. Anthropol. Anz. 62(4), 445-61.

Adamu, L.H., Asuku, A.Y., Taura, M.G., Tela, I.A., Datti, S., Imam, A., 2013. Neck circumference: An upcoming tool of adiposity indices. Niger. J. Basic Clin. Sci. 10, 82-85.

Albin, T. J., 2013. A method to improve the accuracy of pair-wise combinations of anthropometric elements when only limited data are available. Work. 45(4), 493-498.

Albulescu, D., Iliescu, A., Nicolesc, I., 2012. The evaluation of the most important anthropometric variables in adult population in Oltenia County. Curr. Health Sci. J. 38(3), 101-104.

Amini, S. B., Catalano, P. M., Hirsch, V., Mann, L. I., 1994. An analysis of birth weight by gestational age using a computerized perinatal data base, 1975-1992. Obstet. Gynecol. 83(3), 342-52.

Balgir, R. S., 2003. Morphological and regional variations in body dimensions of the Gujjars of different localities in north-western India. Anthropol. Anz. 61(3), 275-285.

Bamaiyi, A. J., Abdulhameed, A., Umar, M., Yahaya, M., 2015. Relationship between weight and mid-upper arm circumference (MUAC) among apparently healthy children of Illela Local Government Area, Sokoto State, NorthWest, Nigeria. Int. J. Curr. Res. Biosci. Plant Biol. 2(1), 56-61.

Bamaiyi, A. J., Adelaiye, A. B., Igbokwe, V. U., 2013. Relationship between anthropometric and haematological parameters among third trimester pregnant women in Sokoto State, Northwest Nigeria. Niger. J. Physiol. Sci., 28(2), 211-219.

Bamaiyi, A. J., Adelaiye, A. B., Igbokwe, V. U., 2015. Effects of anthropometry and parity factors on blood pressure (BP) pattern of third trimester pregnant women in Sokoto, NorthWest, Nigeria. Gynecol. Obstet. (Sunnyvale), 5, 265.

Bamaiyi, A. J., Sule, A.O., Azeez, T. A., 2016. Knowledge of mechanism of action of emergency contraception influences the perception and the seeking attitude in a group of female Nigerian graduates. EC Gynaecol. 3(3), 266-274.

Bharati, S., Demarchi, D. A., Mukherji, D., Vasulu, T. S., Bharati, P., 2005. Spatial patterns of anthropometric variation in India with reference to geographic, climatic, ethnic and linguistic backgrounds. Ann. Hum. Biol. 32(4), 407-444.

Bob-Manuel, I., Udoaka, A., 2008. Relationship between mid-arm circumference and height of children 5 years and below in a semi urban community in Nigeria. Internet J. Nutr. Wellness. 7(2), 1-5.

Borton, C., 2009. Physiological Changes in Pregnancy Patient.co.uk Document ID: 740; version: 25

Bowman, M. L., 2002. The perfidy of percentiles. Arch. Clin. Neuropsychol. 17(3), 295-303.

Calkins, K., Devaskar, S. U., 2009. Fetal origins of adult disease. Curr. Probl. Pediatr. Adolesc. Health Care. 41(6), 158-176.

Calkins, K., Devaskar, S. U., 2011. Fetal origins of 
adult disease. Curr. Probl. Pediatr. Adolesc. Health Care. 41(6), 158-176.

Calle, E. E., Thun, M. J., Petrelli, J. M., Rodriguez, C., Heath, C. W., 1999. Body-mass index and mortality in a prospective cohort of US adults. N. Engl. J. Med. 341(15), 1097-1105.

Carmen, P., 2012. The Evolutionary Significance of Anthropometric Variables on the 'Dark Triad' of Personality: Psychometrically Measured Machiavellianism, Narcissism, and Psychopathy. http://hdl.handle.net/1842/8454

Centers for Disease Control and Prevention, 2001. National Center for Health Statistics. Data Table of Infant Head Circumference-for-age Charts.

Chigbu, C., Aja, L., 2011. Obesity in pregnancy in southeast Nigeria. Ann. Med. Health Sci. Res. 1(2), 135-140.

Chinedu, S. N., Ogunlana, O. O., Azuh, D. E., Iweala, E. E. J., Afolabi, I.S., Uhuegbu, C. C., Idachaba, M. E., Osamor, V. C., 2013. Correlation between body mass index and waist circumference in Nigerian adults: implication as indicators of health status. J. Public Health Res. 2(2), 93 -98.

Chittawatanarat, K., Pruenglampoo, S., Kongsawasdi, S., Chuatrakoon, B., Trakulhoon, V., Ungpinitpong, W., Patumanond, J., 2011. The variations of body mass index and body fat in adult Thai people across the age spectrum measured by bioelectrical impedance analysis. Clin. Interv. Aging. 6, 285-294.

Cooke, R.W.I., Lucas, A., Yudkin, P.L.N., PryseDavies, J., 1977. Head circumference as an index of brain weight in the fetus and newborn. Early Human Develop. 1(2), 145-149.

Dairo, M. D., Fatokun, M. E., Kuti, M., 2012. Reliability of the mid upper arm circumference for the assessment of wasting among children aged 12-59 months in urban Ibadan, Nigeria. J. Biomed. Sci. 8(2), 140-143.

Danborno, B., Elukpo, A., 2008. Sexual dimorphism in hand and foot length, indices, stature-ratio and relationship to height in Nigerians. Internet J. Forensic Sci. 3(1), 1-5.

Ekedigwe, J. E., Pam, S. D., Binitie Sirisena, A.U., Hameed, M., Adegbe, E. O., 2014. Cardiothoracic ratio and body mass index in normal young adult Nigerians. J. Med. Trop. $16,47-51$.

Eregie, C. O., 1991. Assessment of gestational age: the value of a maturity scoring system for head circumference and mid-arm circumference. J.
Trop. Pediatr. 37(4), 182-184.

Figueira, B. B. D., Aparecida, C., Segre, M., 2004. Mid-arm circumference and mid-arm/head circumference ratio in term newborns. Sao Paulo Med. J. 122(2), 53-59.

Ford, E.S., Maynard, L. M., Li, C., 2014. Trends in mean waist circumference and abdominal obesity among US adults, 1999-2012. J. Amer. Med. Assoc. 312(11), 1151-1153.

Fryar, C. D., Gu, Q., Ogden, C. L., 2012. Anthropometric reference data for children and adults: United States, 2007-2010. National Center for Health Statistics. Vital Health Stat. 11(252), 1-48.

Galjaard, S., Pexsters, A., Devlieger, R., Guelinckx, I., Abdallah, Y., Lewis, C., van Calster, B., Bourne, T., Timmerman, D., Luts, J., 2013. The influence of weight gain patterns in pregnancy on fetal growth using cluster analysis in an obese and non-obese population. Obesity. 21, 1416-1422.

Gallagher, D., Visser, M., Sepúlveda, D., Pierson, R. N., Harris, T., Heymsfield, S. B., 1996. How useful is body mass index for comparison of body fatness across age, sex, and ethnic groups? Am. J. Epidemiol. 143(3), 228-239.

Ghazali, S. M., Sanusi, R. A., 2010. Waist circumference, waist to hip ratio, and body mass index in the diagnosis of metabolic syndrome in Nigerian subjects. Niger. J. Physiol. Sci. 25(2), 187-195.

Godhia, M., Nigudkar, M., Desai, R., 2012. Associations between maternal nutritional characteristics and the anthropometric indices of their full-term and pre-term newborns. Pak. J. Nutr. 11, 343-349.

Grellety, E., Golden, M. H., 2016. Weight-forheight and mid-upper-arm circumference should be used independently to diagnose acute malnutrition: policy implications. BMC Nutrition BMC series 2, 10.

Igiri, A., Ekong, M., Ogan, C., Odey, P., 2008. Body mass index measure of young adult Nigerians residents in the Calabar Metropolis. Internet $\mathrm{J}$. Biol. Anthropol. 2(2), 1-4.

Ismaila, O. S., 2009. Anthropometric data of hand, foot and ear of University students in Nigeria. Leonardo J. Sci. 15, 15-20.

Janssen, I., Katzmarzyk, P. T., Ross, R., 2004. Waist circumference and not body mass index explains obesity-related health risk. Am. J. Clin. Nutr. 79(3), 379-384. 
Kramer, M. S., Platt, R. W., Wen, S. W., Joseph, K. S., Allen, A., Abrahamowicz, M., Blondel, B., Bréart, G., 2001. Fetal/infant health study gof the Canadian perinatal surveillance system. A new and improved population-based Canadian reference for birth weight for gestational age. Pediatrics. 108(2), E35.

Krishan, K., Kanchan, T., 2013. Foot length is a functional parameter for assessment of height. Foot (Edinb). 23(1), 54-55.

Kuhle, S., Maguire, B., Ata, N., Hamilton, D., 2015. Percentile curves for anthropometric measures for Canadian children and youth. PLoS One. 10(7), e0132891.

Laghari, G. S., Nizamani, M. A., 2009. The significance of anthropometric measurements to predict mortality in severe protein energy malnutrition. Paediatrics. 15(4), 41 -45.

Lagiou, P., Hsieh, C. C., Trichopoulos, D., Xu, B., Wuu, J., Mucci, L., Tamimi, R., Adami, H. O., Cnattingius, S., 2003. Birthweight differences between USA and China and their relevance to breast cancer aetiology. Int. J. Epidemiol. 32(2), 193-198.

Lawoyin, T. O., 1991. Maternal weight and weight gain in Africans. Its relationship to birth weight. J. Trop. Pediatr. 37(4), 166-171.

Lawoyin, T. O., 1997. The relationship between maternal weight gain in pregnancy, hemoglobin level, stature, antenatal attendance and low birth weight. Southeast Asian J. Trop. Med. Public Health. 28(4), 873-876.

Leddy, M. A., Power, M. L., Schulkin, J., 2008. The impact of maternal obesity on maternal and fetal health. Rev. Obstet. Gynecol. 1(4), 170178.

Luke, A., Durazo-Arvizu, R., Rotimi, C., Prewitt, T.E., Forrester, T., Wilks, R., Ogunbiyi, O. J., Schoeller, D. A., McGee, D., Cooper, R. S., 1997. Relation between body mass index and body fat in black population samples from Nigeria, Jamaica, and the United States. Am. J. Epidemiol. 145(7), 620-628.

Luke, B., Hediger, M., Nugent, C., Newman, R., Mauldin, J., Witter, F., O'Sullivan, M., 2003. Body mass index--specific weight gains associated with optimal birth weights in twin pregnancies. J. Reprod. Med. 48, 217-224.

McDonald, S. D., Han, Z., Mulla, S., Beyene, J., 2010. Knowledge synthesis group. Overweight and obesity in mothers and risk of preterm birth and low birth weight infants: systematic review and meta-analyses. Brit. Med. J. 341, c3428.

Monte, S., Valenti, O., Giorgio, E., Renda, E., Hyseni, E., Faraci, M., De Domenico, R., Di Prima, F. A. F., 2011. Maternal weight gain during pregnancy and neonatal birth weight: a review of the literature. J. Prenat. Med. 5(2), 27-30.

Morgan, K. L., Rahman, M. A., Macey, S., Atkinson, M. D., Hill, R. A., Khanom, A., Paranjothy, S., Husain, M. J., Brophy, S. T., Obesity in pregnancy: A retrospective prevalence-based study on health service utilisation and costs on the NHS. Brit. Med. J. Open. 4, eoo3983.

Mutihir, J. T., Pam, S. D., 2006. Anthropometric and other assessment indices of the newborn in Jos, Nigeria. Ann. Afr. Med. 5(4), 192-196.

Ndu, I. K., Ibeziako, S. N., Obidike, E. O., Adimora, G. N., Edelu, B. O., Chinawa, J. M., Asinobi, I. N., Uleanya, N. D., 2014. Chest and occipito-frontal circumference measurements in the detection of low birth weight among Nigerian newborns of Igbo ethnicity. Ital. J. Pediatr. 40, 81.

Okereke, C. E., Anyaehie, U. B., Dim, C. C., Iyare, E.E., Nwagha, U.I., 2013. Evaluation of some anthropometric indices for the diagnosis of obesity in pregnancy in Nigeria: a crosssectional study. Afr. Health Sci. 13(4), 10341040.

Olorunshola, K. V., Ayo, J. O., Dikki, C. E., Sharaye, K. O., 2013. Physiological and anthropometric correlates of metabolic risk factors among selected non obese adults in Zaria, Northern Nigeria. Int. J. Nutr. Metabol. 5(4), 69-81.

Olusanya, B. O., 2013. Full-term newborns with normal birth weight requiring special care in a resource-constrained setting. Pan. Afr. Med. J. $15,36$.

Oluwafemi, O., Njokanma, F., Disu, E., Ogunlesi, T., 2013. The current pattern of gestational age-related anthropometric parameters of term Nigerian neonates. S. Afr. J. Child Hlth. 7(3), 100-104.

Onankpa, B. O., Airede, K. I., Ahmed, H., Jiya, N. M., 2006. The birth weight of apparently healthy Nigerian newborns in Sokoto. Sahel Med. J. 9(1), 19-22.

Patwari, A. K., Kulkarni, R., Aneja, S., Audu, I., Anthropometric standards of privileged neonates in Maiduguri, Nigeria. Central Afr. J. 
Med. 34(4), 78-84.

Pawar, R. M., Pawar, M. N., 2012. Foot length--A functional parameter for assessment of height. Foot (Edinb). 22(1), 31-34.

Pingle, U., 1984. Anthropometric and genetic distance between Gonds of Central India. Am. J. Phys. Anthropol. 65(3), 291-304.

Rasmussen, K. M., Yaktine, A. L., 2009. Weight gain during pregnancy: Reexamining the guidelines. National, ISBN-13: 978-0-309-13113-1.

Relethford, J. H., 1988. Effects of English admixture and geographic distance on anthropometric variation and genetic structure in 19th-century Ireland. Am. J. Phys. Anthropol. 76(1), 111-124.

Relethford, J.H., Lees, F. C., Crawford, M. H., 1980. Population structure and anthropometric variation in rural western Ireland: Migration and biological differentiation. Ann. Hum. Biol. 7(5), 411-428.

Ricalde, A. E., Velásquez-Meléndez, G., Tanaka, A. C., de Siqueira, A.A., 1998. Mid-upper arm circumference in pregnant women and its relation to birth weight. Rev. Saude Publica. 32(2), 112-117.

Rollins, J. D., Collins, J. S., Holden, K.R., 2010. United States head circumference growth reference charts: Birth to 21 years. J. Ped. 156(6), 907-913.

Schutz, S., Kyle, U. U. G., Pichard, C., 2002. Fatfree mass index and fat mass index percentiles in Caucasians aged 18-98y. Int. J. Obes. 26, 953-960.

Sengupta, M., Karmakar, B., 2007. Inheritance of six anthropometric traits in Vaidyas of West Bengal, India. Ann. Hum. Biol. 34(1), 80-90.

Silventoinen, K., Iacono, W. C., Krueger, R., McGue, M., 2012. Genetic and environmental contributions to the association between anthropometric measures and IQ: A study of Minnesota twins at age 11 and 17. Behav. Genet. 42(3), 393-401.

Snehalatha, C., Viswanathan, V., Ramachandran, A., 2003. Cutoff values for normal anthropometric variables in Asian Indian adults. Diabet. Care. 26(5), 1380-1384.

Ulijaszek, S., Komlos, J., 2009. From a history of anthropometry to anthropometric history in human variation: From the laboratory to the field. Chp. 12, 183 -197.

Ververs, M., Antierens, A., Sackl, A., Staderini, N., Captier, V., 2013. Which anthropometric indicators identify a pregnant woman as acutely malnourished and predict adverse birth outcomes in the humanitarian context? PLoS Curr. 7, 5 .

Vickers, V.S., Stuart, H. C., 1943. Anthropometry in the pediatrician's office: Norms for selected body measurements based on studies of children of North European stock. J. Pediat. 22(2), 155-170.

Wang, Y., Chen, H. J., 2012. Use of Percentiles and Z-Scores in Anthropometry; Chapter 2: Handbook of Anthropometry: Physical Measures of Human Form in Health and Disease. DOI 10.1007/978-1-4419-1788-1_2, (C) Springer Science+Business Media.

Wang, Y., Moreno, L.A., Caballero, B., Cole, T. J., 2006. Limitations of the current world health organization growth references for children and adolescents. Food Nutr. Bull. 27, S175188.

WHO, 1991. Maternal Anthropometry for Prediction of Pregnancy Out-come Memorandum from USAID/WHO/PAHO/ Mother Care Meeting. Bull. WHO, 69 (5), 523-532.

WHO, 1995. Physical status: the use and interpretation of anthropometry. Technical Report Series, No. 854.

WHO, 2001. Healthy Eating for Pregnancy and Lactation Booklet for Mothers by WHO Regional Office for Europe. EUR/01. 5028598.

WHO, 2014. Growth Charts for Canada. Background for the WHO Growth Charts for Canada (March 2014 revision).

Wilcox, M., Gardosi, J., Mongelli, M., Ray, C., Johnson, I., 1993. Birth weight from pregnancies dated by ultrasonography in a multicultural British population. Brit. Med. J. 307(6904), 588-91.

\section{How to cite this article:}

Bamaiyi, A. J., Ladan, K. A., 2019. Human anthropometric values and societal factors - A review. Int. J. Curr. Res. Biosci. Plant Biol. 6(10), 11-21. doi: https://doi.org/10.20546/ijcrbp.2019.610.002 